\title{
The Fruits of Ripe Old Age: Potential Role for Polyphenols in the Modulation of Disorders of Energy Regulation in Aging
}

\section{Evan Paul Cherniack* \\ Geriatrics Clinic, Miami VA Medical Center, USA}

The process of aging is accompanied by many disorders of energy regulation. Frailty, an important pathologic syndrome in the elderly, has multiple causes, but it is characterized by sarcopenia (loss of muscle mass), or alternatively dynapenia (loss of muscle strength). [1] There is a related and concomitant increase in fat mass, sometimes referred to as sarcopenic-obesity. [2] Dementia, another significant problem also has many etiologies but the most common cause, Alzheimer's while also pathophysiologically complex is characterized at a cellular level by mitochondrial dysfunction [3]. Atherosclerosis, an important process and the cause of many diseases prevalent in older age can be the result of an excess of energy intake leading to the storage of excess energy in adipocytes that ultimately cause inflammatory changes resulting in vascular occlusion [4].

A class of molecules known as polyphenols that are found in diet in numerous plant sources modulates the adipocyte lifecycle. Polyphenols, through multiple mechanisms, inhibit adipocyte maturation, lipid storage, differentiation, proliferation and promote apoptosis.

Human trials of polyphenols are now occurring. The best studied polyphenol, resveratrol is being tested as a treatment for metabolic syndrome, cancer, and cognitive dysfunction.

Resveratrol is probably the best-studied polyphenol. The polyphenol retards lipid accretion in adipocytes, in vitro[5]. It reduces levels of genes promoting the maturation of adipoctes, FAS, SREBP1c, C/EBP- $\alpha$, LPL, HSL, and PPAR- $\gamma$. [6] Resveratrol also acts on the mitochondrial gene SIRT3, which promotes the expression of two mitochondrial proteins: uncoupling protein 1 and Mitofusin 2. [6]

Human studies have suggested resveratrol improves systemic glucose and insulin regulation. Ten elderly overweight persons with an abnormal glucose tolerance took 1-2g/d resveratrol for 4 week. Their insulin sensitivity increased, and they had lower postprandial blood glucose levels [7]. Resveratrol ingestion also lowers serum levels of proinflammatory cytokines in man. Ten individuals took a mixture of $100 \mathrm{mg}$ resveratrol and $75 \mathrm{mg}$ of other grape polyphenols with a meal rich in fat and carbohydrates. [8] Peripheral blood monocytes and polymorphonuclear cells from these subjects had lower levels of $1 \mathrm{~L}$ $1 \beta$, thioredoxin, Nrf-2, SOD-2, toll-like receptor 4, CD40, and NDq1. Another ten participants ingested a $40 \mathrm{mg}$ resveratrol supplement a day for a month and a half. [9] Monocytes from the subjects also had reduced inflammatory cytokine levels. In a third investigation, another eleven subjects, all overweight had reduced adipocyte levels and lower blood pressure when they consumed $150 \mathrm{mg}$ daily for 4 weeks [10]. Another dietary polyphenol which might have an important impact on energy regulation in aging is quercetin, which is found in numerous vegetables and fruits. In one study, one hundred seventy-two persons ingested 150mg a day quercetin, for four weeks, had a lower blood pressure and cholesterol. [11] A trial is currently ongoing at the National Institute of Health to determine if quercetin can improve oral glucose tolerance in obese diabetics [12]. Epigallocatechin-3-gallate (EGCG), a polyphenol found in green tea, has been tested on overweight men. Forty-eight men ages 40-65 took 400mg of EGCG or a placebo for two months. [13] Participants who took EGCG had a small but statistically significant reduction in blood pressure.

Research on the applications of polyphenols to treat energy regulatory disorders of aging is only in its early stages. There are many barriers that need to be overcome before polyphenols are practically applied. Polyphenols are rapidly metabolized in the small intestine, and their bioavailability is quite limited, although their metabolites might also be active. [14] In addition, it may be necessary to provide supplementation for long periods of time, perhaps years before clinical manifestations of the disorder become apparent, to successfully treat disease. Polyphenols are found in nature not as isolated substances, but in complex mixtures that are fruits and vegetables. It is not clear if they would be best supplemented as isolated substances, plant extracts, or whole plant forms.

\section{References}

1. Clark BC, Manini TM (2008) Sarcopenia =/= dynapenia. J Gerontol A Biol Sci Med Sci 63: 829-834.

2. Janssen I (2010) Evolution of sarcopenia research. Appl Physiol Nutr Metab 35: $707-712$

3. Querfurth HW, LaFerla FM (2010) Alzheimer's disease. N Engl J Med 362 329-344.

4. Gabriely I, Barzilai N (2001) The role of fat cell derived peptides in age-related metabolic alterations. Mech Ageing Dev 122: 1565-1576.

5. Rayalam S, Della-Fera MA, Baile CA (2008) Phytochemicals and regulation of the adipocyte life cycle. J Nutr Biochem 19: 717-726.

6. Baile CA, Yang JY, Rayalam S, Hartzell DL, Lai CY, et al. (2011) Effect of resveratrol on fat mobilization. Ann N Y Acad Sci 1215: 40-47.

7. Crandall, JP, Oram V, Trandafirescu G, Hawkins M, Reid M, et al. Resveratro Improves Glucose Metabolism in Older Adults with IGT. Abstract \#736-P. American Diabetes Association, 70th Scientific Session. FL; 2010, Orlando.

8. Ghanim H, Sia CL, Korzeniewski K, Lohano T, Abuaysheh S, et al. (2011) A resveratrol and polyphenol preparation suppresses oxidative and inflammatory stress response to a high-fat, high-carbohydrate meal. J Clin Endocrinol Metab 96: 1409-1414

9. Ghanim H, Sia CL, Abuaysheh S, Korzeniewski K, Patnaik P, et al. (2010) An antiinflammatory and reactive oxygen species suppressive effects of an extract of Polygonum cuspidatum containing resveratrol. J Clin Endocrinol Metab 95 E1-E8.

10. Timmers S, Konings E, Bilet L, Houtkooper RH, van de Weijer T, et al. (2011) Calorie restriction-like effects of 30 days of resveratrol supplementation on energy metabolism and metabolic profile in obese humans. Cell Metab 14 612-622.

*Corresponding author: Evan Paul Cherniack, Director, Geriatrics Clinic, Miami VA Medical Center, USA, E-mail: Evan.Cherniack@va.gov

Received March 19, 2012; Accepted March 21, 2012; Published March 30, 2012

Citation: Cherniack EP (2012) The Fruits of Ripe Old Age: Potential Role for Polyphenols in the Modulation of Disorders of Energy Regulation in Aging. J Gerontol Geriat Res 1:e110. doi:10.4172/2167-7182.1000e110

Copyright: (C) 2012 Cherniack EP, et al. This is an open-access article distributed under the terms of the Creative Commons Attribution License, which permits unrestricted use, distribution, and reproduction in any medium, provided the original author and source are credited. 
Citation: Cherniack EP (2012) The Fruits of Ripe Old Age: Potential Role for Polyphenols in the Modulation of Disorders of Energy Regulation in Aging. J Gerontol Geriat Res 1:e110. doi:10.4172/2167-7182.1000e110

11. Egert S, Boesch-Saadatmandi C, Wolffram S, Rimbach G, Muller MJ (2010) Serum lipid and blood pressure responses to quercetin vary in overweight patients by apolipoprotein E genotype. J Nutr 140: 278-284

12. http://clinicaltrials.gov/ct2/show/NCT00065676?term=quercetin\&rank=8.

13. Brown AL, Lane J, Coverly J, Stocks J, Jackson S, et al. (2009) Effects of dietary supplementation with the green tea polyphenol epigallocatechin-3gallate on insulin resistance and associated metabolic risk factors: randomized controlled trial. Br J Nutr 101: 886-894.

14. Hu M (2007) Commentary: bioavailability of flavonoids and polyphenols: call to arms. Mol Pharm 4: 803-806. 